\title{
A strange cloud in the Arctic summer stratosphere 1998 above Esrange $\left(68^{\circ} \mathrm{N}\right)$, Sweden
}

\author{
J. Siebert ${ }^{1}$, C. Timmis ${ }^{2}$, G. Vaughan ${ }^{2}$, K. H. Fricke ${ }^{1}$ \\ ${ }^{1}$ Physikalisches Institut der Universität Bonn, Germany \\ ${ }^{2}$ Physics Department, University of Wales, Aberystwyth, Wales \\ Received: 19 August 1999 / Revised: 13 December 1999 / Accepted: 7 January 2000
}

\begin{abstract}
When the University of Bonn lidar on the Esrange $\left(68^{\circ} \mathrm{N}, 21^{\circ} \mathrm{E}\right)$, Sweden, was switched on in the evening of July 18, 1998, a geometrically and optically thin cloud layer was present near $14 \mathrm{~km}$ altitude or $400 \mathrm{~K}$ potential temperature, where it persisted for two hours. The tropopause altitude was $4 \mathrm{~km}$ below the cloud altitude. The cloud particles depolarized the lidar returns, thus must they have been aspherical and hence solid. Atmospheric temperatures near $230 \mathrm{~K}$ were approximately $40 \mathrm{~K}$ too high to support ice particles at stratospheric water vapour pressures of a few ppmv. The isentropic back trajectory on $400 \mathrm{~K}$ showed the air parcels to have stayed clear of active major rocket launch sites. The air parcels at $400 \mathrm{~K}$ had travelled from the Aleutians across Canada and the Atlantic Ocean arriving above central Europe and then turned northward to pass over above the lidar station. Parcels at levels at $\pm 25 \mathrm{~K}$ from $400 \mathrm{~K}$ had come from the pole and joined the $400 \mathrm{~K}$ trajectory path above eastern Canada. Apparently the cloud existed in a filament of air with an origin different from those filaments both above and below. Possibly the $400 \mathrm{~K}$ level air parcels had carried soot particles from forest wild fires in northern Canada or volcanic ash from the eruption of the Korovin Volcano in the Aleutian Islands.
\end{abstract}

Key words: Atmospheric composition and structure (aerosols and particles; biosphere-atmosphere interactions) - Meteorology and atmospheric dynamics (middle atmospheric dynamics)

\section{Introduction}

Clouds in the polar stratosphere (PSC) are usually thought of in terms of the winter season, when temperatures fall sufficiently low for cloud formation.

Correspondence to: $\mathrm{K}$. H. Fricke
The importance of such winter PSCs for the destruction of stratospheric ozone is well established (cf. Solomon, 1999). The visually spectacular variants of the PSCs are the mother-of-pearl clouds (MPC). Hesstvedt (1958) investigated the annual variation of MPCs and similar clouds above Norway. Out of 126 reports only six are for the months May to August. Four of them were about iridescent clouds in the years 1871-1892 without height determinations and the remaining two Hesstvedt (1958) classified as 'not reliable'. The statistics by Stanford and Davis (1974) lists 156 reports about sightings of MPCs in the northern hemisphere from 1870 to 1972 , of which only four were for the summer period June to September, one case each in Great Britain, the USSR, and two cases in New Mexico, USA; one of the latter is associated with the White Sands Missile Range. Lidars have occasionally detected unusual, short lasting clouds in the upper stratosphere (Clemesha and Nakamura, 1972; Thomas et al., 1984) of speculated origin and in the lower stratosphere (Sassen and Horel, 1990), which the authors could trace to a minor volcanic eruption in Guatemala.

Stratospheric clouds in (polar) summer obviously are rare events. We were very surprised when we detected such a cloud with our lidar in mid-July 1998. In this work we present the observation and explore potential mechanisms for the formation of this cloud.

\section{Measurements}

The University of Bonn backscatter lidar is located on the Esrange in northern Sweden $\left(67.9^{\circ} \mathrm{N}, 21.1^{\circ} \mathrm{E}\right)$. It was operated from mid-July to mid-August 1998 to search for cloud formation in the middle atmosphere. When the lidar operation commenced on July 18, 1998 at 2043 UT the sky was partially cloudy, and in addition to the signatures of tropospheric clouds we also detected a cloud layer at $14 \mathrm{~km}$ altitude in the lidar returns. Knowing about this high altitude cloud, we could also visually identify it in the sky when looking towards the newly set Sun. It had the pale-greyish appearance we 
know so well from observations of polar stratospheric clouds in winter. During the next two hours the signal strength from this cloud initially increased, then it later faded away, and had disappeared by 2350 UT. The mean backscatter profile for the $2 \mathrm{~h}$ of observations is shown in Fig. 1. About 40 min later the signal from the clouds in the upper troposphere increased strongly when a warm front moved in from the south-east. Observations continued until 0145 UT, when the solar background had overwhelmed the lidar signal above $35 \mathrm{~km}$ altitude in an increasingly cloudy, i.e. scattering sky. The 14-km cloud had not returned in the second half of the observation period. The temporal evolution of the signal strength and altitude from all clouds decks is shown in Fig. 2. The cloud initially appeared at $14.1 \mathrm{~km}$ above mean sea level and gradually increased its altitude by $600 \mathrm{~m}$ during the two hours of observations. The full width at half maximum was about $300 \mathrm{~m}$. The lidar range gate was set at $150 \mathrm{~m}$. The altitude of $14 \mathrm{~km}$ corresponds to a potential temperature of $400 \mathrm{~K}$. The observation duration and the wind speed imply that the cloud extended at least $90 \mathrm{~km}$ along the wind direction.

The peak backscatter ratios were 4.3 and 39 for parallel and perpendicular polarization, respectively, at a wavelength of $532 \mathrm{~nm}$ in $5 \mathrm{~min}$ integration time. The derived aerosol depolarization factor is $4 \%$, therefore the particles in the clouds must have been aspherical and
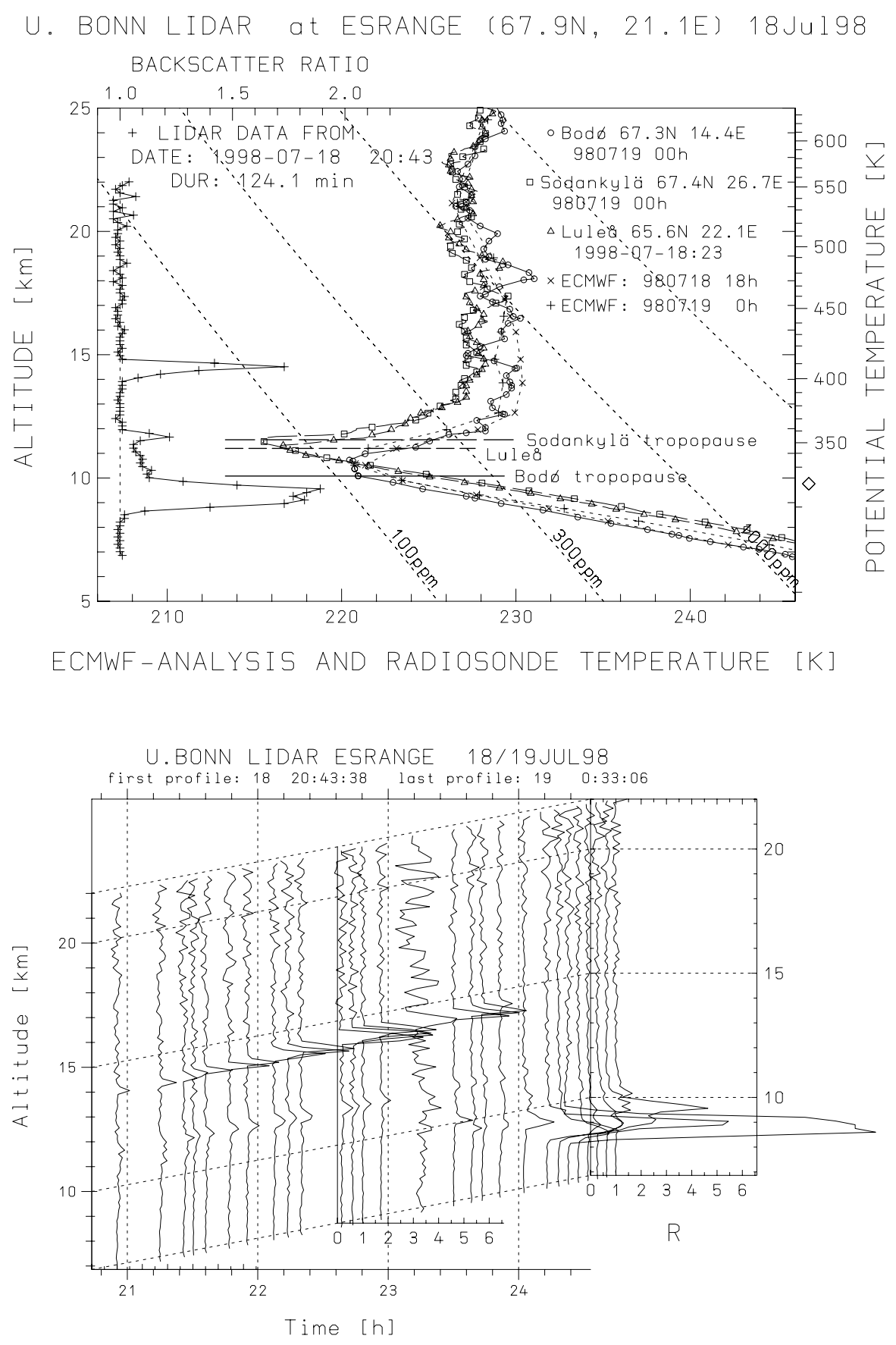

Fig. 1. The left points show the lidar backscatter ratio at wavelength $532 \mathrm{~nm}$ averaged in time from 2043 to 2247 UT on July 18, 1998. Temperature profiles (right curves) from ECMWF analyses and the midnight radiosondes launched at Bodø, $290 \mathrm{~km}$ west of Esrange, Sodankylä, $245 \mathrm{~km}$ east, and Luleå, $265 \mathrm{~km}$ south. Dashed oblique lines give water vapour saturation temperatures for hypothetical assumptions about stratospheric water vapour mixing ratios from 100 to $3000 \mathrm{ppmv}$
Fig. 2. Temporal evolution of the clouds above Esrange on July 18, 1998, from 2043 to 0033 UT. Shown are stacked profiles of the backscatter ratio for the parallel polarization returns at $532 \mathrm{~nm}$ wavelength 
hence solid. The peak backscatter ratio converts to a backscatter coefficient of $910^{-4} / \mathrm{km}$ sr. The peak integrated backscatter coefficient across the cloud was $410^{-4} /$ sr. The atmospheric background signal shows a small offset across the cloud, which implies a transmission loss, from which we estimate the cloud vertical optical depths to be $\tau=0.02 \pm 0.01$. From the optical thickness and the integrated backscatter coefficient we estimate the lidar ratio to be about 60 , which implies that particle radii are smaller than $0.5 \mu \mathrm{m}$.

On this same evening a "strange looking" cloud, pale-greyish in colour and thread-shaped in structure very much like polar stratospheric clouds in winter, was seen by naked eye from the town of Kiruna, $35 \mathrm{~km}$ west of the lidar (K. Stebel, private communication). There was no cloud signature in the simultaneous data of the ALOMAR lidar station, which is located $260 \mathrm{~km}$ westnorthwest. The cloud does not show up in maps of the TOMS aerosol index, which is compatible with the limiting sensitivity of TOMS (Torres et al., 1998).

Supporting meteorological data, i.e. local temperature profiles from ECMWF analyses and from the radiosondes at Bodø in Norway, Luleå in Sweden, and Sodankylä in Finland are also shown in Fig. 1.

\section{Discussion}

The temperature profiles from the midnight radiosondes each show a single tropopause at $10.1 \mathrm{~km}, 11.3 \mathrm{~km}$, and $11.5 \mathrm{~km}$ altitude (see Fig. 1); the difference in tropopause altitude shows that a warm front had passed Lule aring; and Sodankylä but had not yet arrived at Bodø. These local measurements are supported by the ECMWF analyses for 18 and 0 UT on the 18th and 19th July respectively. The cloud observed at $14.4 \pm 0.3 \mathrm{~km}$ above Esrange thus lies clearly in the stratosphere. It is also clear from the temperature profiles that for average stratospheric water vapour mixing ratios of less than $10 \mathrm{ppmv}$, the stratospheric temperatures at $14-15 \mathrm{~km}$ altitude are too warm by $40 \mathrm{~K}$ to sustain an ice cloud. It would require at least a 100-fold increase in the stratospheric water vapour mixing ratio to form clouds at ambient temperatures of $230 \mathrm{~K}$.

In principle there are a number of processes, which can lead to the formation of such a cloud: there might have been an (artificial) injection of solid particles and water vapour into the stratosphere from a volcanic eruption or from a rocket launch with subsequent transport to northern Sweden. Supersonic transports (SST) travel at these altitude levels in the lower stratosphere and form contrails. A meteor or a decaying satellite might have penetrated to low altitudes leaving debris. Higher than usual levels of water could have entered laterally into the northern stratosphere from the upper tropical troposphere. Substantial cooling of the stratosphere can be induced by gravity waves excited at orographic features or frontal systems, which could produce saturation in the stratosphere, which in turn leads to cloud formation; such a process is not limited to water ice but might involve formation of sulphuric acid tetrahydrate. Vertical convergence could have concentrated the background aerosol into a cloud-like sheet. Deep convection might have carried lower troposphere dust into the stratosphere.

We can immediately reject hypotheses dealing with liquid, i.e. spherical particles such as the background aerosol without involving a physical phase transition, as the observed depolarization requires solid particles. In the Zebre campaign it was observed that the contrail formed by the Concorde SST in the cold winter polar stratosphere dissolved on time scales of a few minutes (J. P. Pommereau et al., Observations of the Contrail of a Concorde Aircraft in the Winter Arctic Stratosphere: Interpretation and Implication of Impact Water Vapour Emission by HSCTs, manuscript in preparation, 1999); the SST contrail hypothesis for our PSC may therefore be ruled out as well.

Except for local wave generation all other possibilities involve air parcel transport from the location of the atmosphere modification event to northern Sweden. A cluster of isentropic back trajectories was computed based on winds from the ECMWF analyses ending above and near Esrange at 0 UT on July 19 in the $400 \mathrm{~K}$ level, and are shown in Fig. 3 as well as trajectories at 375 and $425 \mathrm{~K}$. The statistical results from Sparling et al. (1997) suggest that the parcels have probably spread by no more than $\delta \Theta \approx 10 \mathrm{~K}$ during a travel time of less than a month, thus largely retaining their identity.

All back trajectories to northern Sweden approach from central Europe and all have crossed the North Atlantic in the 50 to $60^{\circ} \mathrm{N}$ latitude band. Above eastern North America the trajectories separate; the $400 \mathrm{~K}$ Esrange trajectories had crossed Canada equatorward of $70^{\circ} \mathrm{N}$ coming from the northern Pacific. The trajectories on levels $25 \mathrm{~K}$ higher and lower had come from poleward of $70^{\circ} \mathrm{N}$. These trajectories suggest that a thin filament of air with an origin different from surrounding lower and higher levels had arrived at Esrange at the time of our observations. Above the Pacific near $50^{\circ} \mathrm{N}$, $150^{\circ} \mathrm{W}$ the $400 \mathrm{~K}$ cluster separates: one part swings south of the Aleutian islands, crosses the Northern Pacific to arrive at the Asian mainland north of Japan, while the other part, including the trajectories ending closest to Esrange, goes into a loop over the Aleutian Islands then crosses the Pacific to pass over northern Japan on to mainland Asia.

The filament at $400 \mathrm{~K}$ had formed about one week before the arrival at Esrange, with a thickness of less than $50 \mathrm{~K}$ or $3 \mathrm{~km}$. As the particles remained in the filament there exists an upper limit to their settling speed of $5 \mathrm{~mm} / \mathrm{s}$ and hence to the particle radius of at most $2 \mu \mathrm{m}$ (Müller and Peter, 1992). This value is compatible with the upper limit of $0.5 \mu \mathrm{m}$ for the particle size derived from the optical properties of the clouds. The observed rise in the cloud altitude reflects dynamic lifting of the air and does not invalidate sedimentation at these terminal velocities.

None of the back trajectories passes over those Russian cosmodromes from which rockets were 


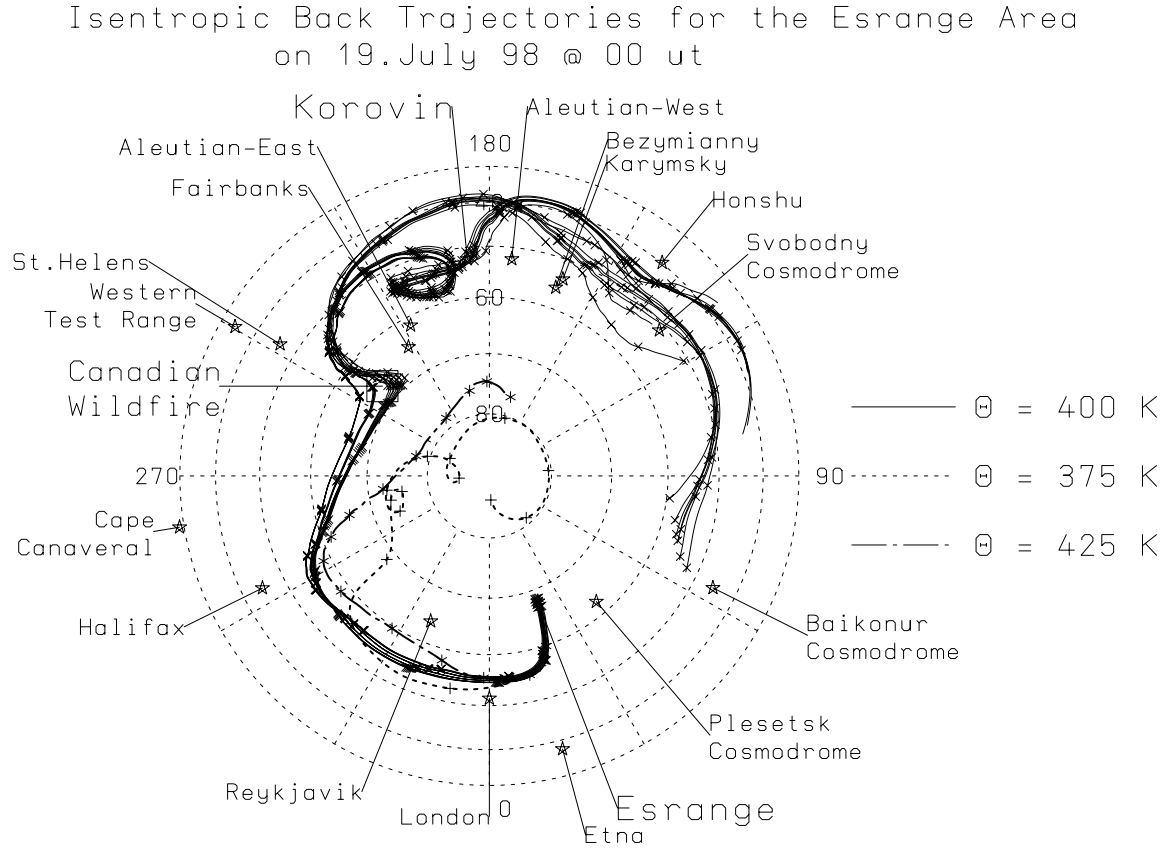

Fig. 3. Isentropic back trajectories ending above Esrange at 0 UT on July 19, 1998 at the cloud level $400 \mathrm{~K}$ and $25 \mathrm{~K}$ above and below the cloud level (approximately $1-2 \mathrm{~km}$ altitude difference) launched in the period mid-June to mid-July 1998, and none of the major western rocket launch areas is crossed. Forward trajectories from the cosmodromes do not arrive over northern Scandinavia. We therefore rule out the rocket exhaust hypothesis. We cannot rule out the meteor or satellite decay hypothesis as the air parcels spent much of their time over water and sparsely populated land where such a singular event could go unnoticed.

The $400 \mathrm{~K}$ back trajectories which looped over the Aleutians, passed their easternmost longitude $\left(152^{\circ} \mathrm{W}\right)$ on July 5 and left the Aleutians when passing their westernmost longitude $\left(174^{\circ} \mathrm{E}\right)$ on June 23 . During this time span an eruption of the Korovin Volcano $\left(52.4^{\circ} \mathrm{N}\right.$, $174.2^{\circ} \mathrm{W}$ ) was reported as ongoing by the Alaska Volcano Observatory (1998) for June 30, 1830 UT with an eruption column estimated to be as high as $4.9 \mathrm{~km}$ by an aircraft pilot. At this time the Esrange air parcels were approximately $1000 \mathrm{~km}$ away from Korovin. While the agreement is close in time and space on a global scale, it is not perfect. Also, the reported height for the eruption column is insufficient. From the available observational evidence (Alaska Volcano Observatory, 1998) it is believed to be highly unlikely that Korovin injected material into the stratosphere (D. Schneider, personal communication).

As the $400 \mathrm{~K}$ air parcels moved towards Europe they passed over northern Canada when intense forest fires were burning. The Canadian Centre for Remote Sensing uses AVHRR images to remotely sense wild fires ( $\mathrm{Li}$ et al., 1997). Such maps of fire locations show numerous fires in July 1998 several hundred kilometres south of the trajectory. In the night of July $09 / 10$ there was a much closer passage $(\approx 180 \mathrm{~km})$ near a long-burning wild fire next to the Mackenzie River $\left(67^{\circ} \mathrm{N}, 130^{\circ} \mathrm{W}\right)$. AVHRR images from NOAA satellites showed deep convection occurring in this region on this night.
Both volcanoes and forest fires release large amounts of energy in the lower troposphere. Given sufficient heat and proper atmospheric conditions, in particalur moisture, either released in the event or entrained from the environment, convective cells may develop with sufficient buoyancy to penetrate the tropopause and deposit (small) particles of soot (fire) or silicate dust (volcano) into the stratosphere. Such scenarios have been modelled for explosive eruptions of volcanoes by Sparks et al. (1997) and for convective flows above wild fires by Gostintsev et al. (1991). The visibility of such events depends on the contrast such a soot or dust filled convective cell will create in the atmosphere under the given local illumination. Both soot and dust particles are solid and will produce a depolarized signal in our lidar data. Either source could explain the observed cloud.

In principle the observed cloud could have been caused by high amounts of water vapour, which might have been injected laterally into the stratosphere in the subtropics or in a deep convection event and then advected to Esrange. However, the trajectories of the air parcels exclude any subtropical origin of the particles and a surface temperature corresponding to a $400 \mathrm{~K}$ equivalent potential temperature does not exist over the latitude bands the air parcels have travelled. In addition any ice cloud would have evaporated with the increasing temperature as it is transported toward polar latitudes. It is conceivable that in the approaching frontal system a singular event had adiabatically pushed a parcel of air from the tropopause region 3 to $4 \mathrm{~km}$ upwards leading to cooling by $30-40 \mathrm{~K}$, which would be sufficient for cloud formation. However, in the almost isothermal lower stratosphere such a parcel would oscillate with a Brunt-Väisälä period of $5 \mathrm{~min}$, which is not observed in the $2 \mathrm{~h}$ of lidar data. Temperature oscillations (see Fig. 1) in the nearby radiosonde data do not exceed $2 \mathrm{~K}$, which is compatible with the envelope for such 
oscillations predicted on this day by the parametrization scheme of Bacmeister (1993) for orographically induced lee waves. And finally the radiosondes do not show multiple tropopauses on this day.

\section{Conclusion}

In mid-summer 1998 we observed a depolarizing polar stratospheric cloud with our backscatter lidar in northern Sweden. At stratospheric temperatures and humidities a water-ice cloud would have evaporated during the 2-h duration of the observation. The observed particles must have been injected into the stratosphere. Isentropic back trajectories suggest that a thin filament of air had arrived above the lidar, which in the previous three weeks had travelled from the Aleutian Islands via northern Canada, the Atlantic Ocean to northern Sweden, which delimits the geographical source region.

Potential sources for the observed particles are soot from forest fires in Canada or silicate dust from the eruption of the Korovin volcano in the Aleutian islands. Neither of these two sources is perfect in the sense that the back trajectories passed directly over the source region on the event day. However, back trajectories calculated for several weeks duration necessarily accumulate errors from assumed meteorological wind fields and deviations from the isentropic conditions. Allowing for such errors there is acceptable agreement for both of the sources.

From the experimental data it is not possible to decide with certainty which of the potential sources actually provided the observed particles in the stratosphere. From the plausibility point of view, there are doubts that the Korovin eruption injected material into the stratosphere (D. Schneider, personal communication). Deep convection was observed in the McKenzie river region which, enhanced by the energy release from the fire, might have injected material into the lower stratosphere. This leaves smoke particles from the wildfires as the more likely source of this unusual cloud in the Arctic summer stratosphere.

Acknowledgements. We are indebted to J. G. Goldammer from the Global Fire Monitoring Center, to D. Schneider from the Alaska Volcano Observatory, and to H. Klinkrad from the European Space Operation Centre who all helped with information in their fields of expertise. Esrange provided hospitality and support for the lidar observations. FMI Sodankylä, DNMI Bodø, and SMHI Lule aring; made their radiosonde soundings available, and ECMWF the T106 analyses, which were disseminated by NILU. $\mathrm{BMBF}$ funded the lidar operations as part of the German ozone research program.

Topical Editor D. Murtagh thanks a referee for his help in evaluating this paper.

\section{References}

Alaska Volcano Observatory, Korovin, Aleutian Islands, Alaska, USA, Bull. Global Volcan. Netw., 23, (6) 1998.

Bacmeister, J., Mountain-wave drag in the stratosphere and mesosphere inferred from observed winds and a simple mountain-wave parameterization scheme, J. Atmos. Sci., 50, 377-399, 1993.

Clemesha, B. R., and Y. Nakamura, Dust in the upper atmosphere, Nature, 237, 328-329, 1972.

Gostintsev, Y. A., N. P. Kopylov, A. M. Ryzhov, and I. R. Khazanov, Numerical modeling of convective flows above large fires at various atmospheric conditions, translated from Fiz. Goren. Vzryva, 27, 10-17, 1991.

Hesstvedt, E., Mother of pearl clouds in Norway, Geophys. Nor. XX(10), 1-29, 1958.

Li, Z., J. Cihlar, L. Moreau, F. Huang, and B. Lee, Monitoring fire activities in the boreal ecosystem, J. Geophys. Res., 102, 29 61129 624, 1997.

Müller, R., and T. Peter, The numerical modelling of the sedimentation of polar stratospheric clouds particles, Ber. Bunsenges. Phys. Chem., 96, 353-361, 1992.

Sassen, K., and J. D. Horel, Polarization lidar and synoptic analyses of an unusual volcanic aerosol cloud, J. Atmos. Sci., 47, 2881-2889, 1990.

Sparks, R. S. J., M. I. Bursik, S. N. Carey, J. S. Gilbert, L. S. Glaze, H. Sigurdsson, and A. W. Woods, Volcanic plumes, John Wiley and Sons, Chichester, 1997.

Solomon, S., Stratospheric ozone depletion: a review of concepts and history, Rev. Geophys., 37, 275-316, 1999.

Sparling, L. C., J. A. Kettleborough, P. H. Haynes, M. E. McIntyre, J. E. Rosenfield, M. R. Schoeberl, and P. A. Newman, Diabatic cross-isentropic dispersion in the lower stratosphere, J. Geophys. Res., 102, 25 817-25 829, 1997.

Stanford, J. L., and J. S. Davis, A century of stratospheric cloud reports: 1870-1972, Bull. Am. Meteorol. Soc., 55, 213-219, 1974.

Thomas, L., D. P. Wareing, and D. B. Jenkins, Observation of a thin layer of material in the upper stratosphere, Nature, 312, 627-628, 1984.

Torres, O., P. K. Bhartia, J. R. Herman, Z. Ahmad, and J. Gleason, Derivation of aerosol properties from satellite measurements of backscattered ultraviolet radiation: theoretical basis, J. Geophys. Res., 103, 17 099-17 110, 1998. 